\title{
Antimicrobial Effect of Chitosan against Periodontal Pathogens Biofilms
}

\author{
Eduardo M Costa ${ }^{1}$, Sara Silva ${ }^{1}$, Cristina Pina ${ }^{2}$, Freni K Tavaria ${ }^{1}$ and Manuela Pintado ${ }^{1 *}$ \\ ${ }^{1}$ CBQF - Center for Biotechnology and Fine Chemicals - Laboratory Associate, School of Biotechnology, Portuguese Catholic University Oporto, Rua Doutor \\ Antonio Bernardino de Almeida, Portugal \\ ${ }^{2}$ Faculty of Health Sciences, University Fernando Pessoa, Portugal
}

Received: February 26, 2014; Accepted: March 10, 2014; Published: March 12, 2014

*Corresponding author: Manuela Pintado, CBQF-Center of Biotechnology and Fine Chemicals - Laboratory Associate, School of Biotechnology, Portuguese Catholic University Oporto, Rua Doutor Antonio Bernardino de Almeida, Portugal, Tel: +351-22-55-80-097; Fax: +351-225-090-351-420-0072; E-mail: emcosta@porto.ucp.pt

\begin{abstract}
Over the years authors have established that chitosan possesses significant antimicrobial activity against planktonic bacteria however, little is known about the effect of chitosan upon sessile microbial communities. The aim of this work was to assess the effect of chitosan against 5 periodontal pathogens, Porphyromonasgingivalis, Prevotellaintermedia, Prevotellabuccae, Tanerellaforsythensis and Aggregatibacter actinomycetemcomitans biofilm formation. The results obtained show that both high molecular weight and low molecular weight chitosan were capable of inhibiting biofilm formation and biofilm associated phenomena. Sub-MIC concentrations of chitosan inhibited single species biofilm formation up to $90 \%$ and dual species biofilms formation up to $80 \%$. Furthermore analysis of the effect of chitosan upon quorum sensing showed inhibition values that reached $70 \%$ after $24 \mathrm{~h}$ exposure to chitosan. The results obtained open new possibilities in the fight against biofilm formation in the oral cavity and the prevention of undesirable microbiological colonization following dental treatments.
\end{abstract} Sensing

Keywords: Biofilm; Chitosan; Dual species; Sub-MIC; Quorum

\section{Introduction}

Dental plaque is a dynamic biofilm established in an always evolving environment in which microorganisms have to be capable of adhere to fluid bathed surfaces in order to survive and colonize [1,2]. In the oral cavity, microorganisms dwell in specific niches and biofilms are formed upon teeth, prostheses and mucosal surfaces. If it was unchecked, these biofilms will lead to the development of caries and periodontal diseases [3]. The dental plaque is host to more than 800 species of microorganisms, while some of them are capable to directly adhere to the oral cavity tissues- Streptococcus oralis, Streptococcus sanguinis, and Streptococcus mitis, others like Aggregatibacter actinomycetemcomitans and Prevotellaintermedia need coaggregation partners in order to do so $[2,4]$.

Usually, oral biofilms are regarded as aetiological agents associated with dental caries and periodontitis, with the latter implying the destruction of the support structure of the tooth, bleeding and, eventually, tooth loss $[2,5,6]$. Despite the variety of microorganisms that colonize the oral cavity, most bacteria associated with periodontal disease are Gram negative anaerobic bacteria such as Aggregatibacter actinomycetemcomitans and several Bacteroidetes species e.g. Porphyromonasgingivalis [7]. The common treatment of dental plaque is a two-step process that encompasses a mechanical treatment in conjunction with an antimicrobial application $[2,6,8]$. However, the usage of antimicrobials in the oral cavity is greatly hindered by the presence of biofilm. This reduced susceptibility of biofilms to antimicrobials associated with an overall increase of drug resistance in bacteria, has led to an ongoing quest for new antimicrobials to be used in oral healthcare [8-10]. In this regard chitosan may be an efficient yet natural antimicrobial alternative, while controlling oral biofilm formation.

Chitosan, a natural polysaccharide derived from chitin, has both a proven antimicrobial activity (against fungi, algae and bacteria) [11,12] and bioadhesive capabilities thus making it an interesting prospect as a bioactive component in oral health products [13]. Most of the published works concerning the effects of chitosan report its bactericidal action against planktonic microorganisms, but limited information is known about its activity upon bacterial adhesion and biofilm formation [10,1416]. Considering that the effect of chitosan upon oral pathogens biofilms is still under exploration, the main objective of this study was to assess chitosan's potential as a possible antibiofilm agent capable of hampering biofilm formation by periodontal pathogens.

\section{Material and Methods}

\section{Microorganisms}

Five of the seven microorganisms used in this study were obtained from the culture collection of the Goteburg University (CCUG) (Sweden)-Prevotellabuccae (CCUG 15401) an isolate from periodontitis; Tannarellaforsythensis (CCUG 51269) an isolate from human deep periodontal pockets; Aggregatibacter actinomycetemcomitans (CCUG 13227) origin not discriminated; Chromobacteriumviolaceum (CCUG 37577) origin not discriminated; Streptococcus mutans (CCUG 45091) origin not 
descriminated. Porphyromonasgingivalis was obtained from Institute Pasteur (France) (9704 CIP 103683T) and a clinical isolate of Prevotellaintermedia. All microorganisms were grown in Wilkins-Chalgrens broth (WCB) (Oxoid, England), with the exception of $C$. violaceumthat was grown in Luria Bertani Broth (LB) (Invitrogen, United Kingdom), and all inocula were prepared overnight.

\section{Sources and preparation of chitosan solutions}

High and low molecular weight chitosan (HMW and LMW, respectively) were obtained from Sigma-Aldrich (St. Louis, USA). High molecular weight chitosan presented a Deacetylation Degree (DD) $>75 \%$ and a Molecular Weight (MW) of $624 \mathrm{kDa}$. Low molecular weight chitosan presented a DD between 75 and $85 \%$ and a MW of $107 \mathrm{kDa}$.

Chitosan solutions were prepared in $1 \%(\mathrm{v} / \mathrm{v})$ solution of glacial acetic acid 99\% (Panreac, Barcelona, Spain). Chitosan was added to $1 \%$ acetic acid to the desired concentration. Afterwards, the solution was stirred overnight at $50^{\circ} \mathrm{C}$ to promote a complete dissolution of chitosan. The $\mathrm{pH}$ was adjusted with $\mathrm{NaOH}$ (Merck, Darmstad, Germany) to a final value of 5.6-5.8 and solutions were stored at $4^{\circ} \mathrm{C}$.

\section{Tube test}

The screening for the effect of chitosan on biofilm formation was adapted from Christensen, et al. [17]. Transparent $25 \mathrm{ml}$ plastic tubes were inoculated at $1 \%(\mathrm{v} / \mathrm{v})$ in WCB supplemented with $5 \%(\mathrm{~m} / \mathrm{v})$ sucrose. Chitosan was added at sub-MIC (at $1 / 2$ and $1 / 4$ of the MIC) concentrations selected according to the MIC results determined by Costa, et al. [9] (Table 1). Each tube was incubated in horizontal position at $37^{\circ} \mathrm{C}$ for $72 \mathrm{~h}$ in a rectangular anaerobiosisjar (AnaeroPack, Mitsubishi gas chemical company, Japan). Tubes with inoculum only and with medium only were used as positive and negative controls, respectively.

After incubation, the contents of each tube were carefully removed and discarded. Subsequently $2 \mathrm{ml}$ of crystal violet solution (Merck, Darmstad, Germany) were added to each tube and left to react for $5 \mathrm{~min}$ on a roll and tilt mixer (Movil-Rod, J.P. Selecta, Barcelona, Spain) for homogeneous staining. After that, the staining solution was discarded, the tubes inverted and left to dry overnight at room temperature.

Biofilm formation was judged qualitatively by observation of a visible film lining the walls of the tube and estimated as absent $(0)$, weak $(+)$, moderate $(++)$ or strong $(+++)$. All assays were done in triplicate.

\section{Microtiter-plate test}

Quantification of biofilm production in batch and fed-batch was carried out by adapting the protocol of Stepanovic et al. [18]. Briefly, in a flat bottom 96 microplate wells were filled with 200 $\mu \mathrm{l}$ of test solutions with chitosan added at sub-MIC concentration. Biofilms were formed in batch and in fed-batch mode. In the first, the plate was incubated at $37^{\circ} \mathrm{C}$ for $48 \mathrm{~h}$ in a rectangular jar. In the second, the medium was renewed every $24 \mathrm{~h}$. These assays lasted 96 and $198 \mathrm{~h}$ at $37^{\circ} \mathrm{C}$. All assays were performed in triplicate in WCB with $5 \%$ sucrose.
Table 1: Chitosan sub-MIC tested for each bacterium in $\mathrm{mg} / \mathrm{mL}$. Values based on those previously described by Costa et al. [9].

\begin{tabular}{|c|c|c|c|c|}
\hline & \multicolumn{2}{|c|}{ HMW $(\mathbf{m g} / \mathbf{m L})$} & \multicolumn{2}{c|}{ LMW $(\mathbf{m g} / \mathbf{m L})$} \\
\hline & $\mathbf{1 / 2}$ & $\mathbf{1 / 4}$ & $\mathbf{1 / 2}$ & $\mathbf{1 / 4}$ \\
\hline P. gingivalis & 0.5 & 0.25 & 0.5 & 0.25 \\
\hline T. forsythensis & 0.5 & 0.25 & 1.5 & 0.75 \\
\hline P. buccae & 1.5 & 0.75 & 0.5 & 0.25 \\
\hline A. actinomycetemcomitans & 2.5 & 1.25 & 1.5 & 0.75 \\
\hline P. intermedia & 0.5 & 0.25 & 1.5 & 0.75 \\
\hline
\end{tabular}

To visualise biofilms, the contents of each well were discarded and then washed 3 times with sterile deionised water in order to remove non-adherent cells. The remaining attached bacteria were fixed with $200 \mu \mathrm{l}$ of ethanol (Panreac, Barcelona, Spain) for $15 \mathrm{~min}$. Ethanol was discarded and the wells were air dried. After that, $200 \mu \mathrm{l}$ of crystal violet solution were added to the wells, the excess stain was removed after $5 \mathrm{~min}$ by rinsing the plate under tap water, followed by air drying. Biofilm formation was quantified by measuring the Optical Density at $630 \mathrm{~nm}$ using a microplate reader (FLUOstar, OPTIMA, BGMLabtech).

All experiments were done in triplicate for each bacterium. Optical density values from wells with only WCB were used as negative controls. A positive control with sterile deionised water for each bacterium was used.

Results for this test were given as percentage of biofilm formation inhibition applying the following formula:

$\%$ biofilm formation inhibition $=100-\left(O D_{\text {assay }} / O D_{\text {co }}\right.$ ) 100

\section{Dual species biofilms}

Quantification of the effect of chitosan upon biofilms formed by two different bacteria (S. mutans and P. intermedia; S. mutans and P. gingivalis) was evaluated as described by Costa, et al. [10].

\section{Quorum sensing (QS) inhibition assay}

Screening of the QS inhibitory activity of HMW and LMW chitosan was carried out based on their ability to inhibit the production of the purple pigment violacein by C.violaceum. The assay was performed through the adaptation of the protocol described by Pitlovanciv, et al. [19]. Briefly, in a 96 wells microplate, wells were filled with $200 \mathrm{ml}$ of test solution with chitosan added at sub-MIC concentrations. Simultaneously a positive control, where chitosan was substituted with water, was also assayed. Following that the plate was incubated at $37^{\circ} \mathrm{C}$ during $24 \mathrm{~h}$ in a microplate reader (FLUOstar, OPTIMA, BGM Labtech) with OD being measured at $577 \mathrm{~nm}$ for violacein production and at 660 for bacterial growth. All assays were performed in triplicate.

\section{Statistical treatment}

The statistical differences in the methods were evaluated using PASW Statistics v. 18.0.0 (New York, USA).The normality of the results distribution was evaluated through Shapiro-Wilk's test. The differences were evaluated using one way ANOVA test 
associated with Scheffe's test (for normal distributions) or the non-parametric Mann-Whitney Test for the rest. The differences were considered significant at a 0.05 level.

\section{Results and Discussion}

\section{Tube test}

The experiments performed in our study enabled us to measure the effect of chitosan on adherence and on biofilm formation of the tested bacteria. A screening of the inhibitory effect of chitosan on biofilm formation was performed by test tube method and results are presented in Table 2.

In this method, first described by Christensen et al. [17], the results obtained are qualitative and more subjective as they are obtained by visual inspection. However, this method provides a valuable screening of the capabilities of chitosan to inhibit biofilm formation by the various bacterial species under study. The absence of film (0) was compared with negative control (medium without inoculum) and strong biofilm formation (+++) with positive control (bacteria without chitosan). The levels weak (+) and moderate (++) were intermediate levels.

The results showed that the chitosan effect did not reveal a clear pattern with results varying from complete absence of biofilm to moderate biofilm formation according to the microorganism and MW. Chitosan showed a low inhibitory effect upon $P$. intermedia biofilm formation but was capable of completely inhibiting biofilm formation by $P$. gingivalis, with no difference between MW and concentrations tested being found. For the remaining bacteria it was not possible to infer any conclusions from this screening.

\section{Microtiter-plate assay}

As this method is a quantitative assay and, consequently, more accurate than the tube test, these results will shed a better light upon chitosan's action on biofilm formation.

As can be seen from inspection of Figure 1, chitosan was capable of inhibiting biofilm formation in percentages higher to $50 \%$ for all studied bacteria, with the only exception being $0.25 \mathrm{mg} / \mathrm{ml}$ of HMW chitosan for T. forsythensis Cerca, et al. [20] stated that significant differences were found between batch and fed-batch assays, with the strains producing less biofilm when grown in batch systems. In our case, both assays had a

Table 2: Chitosan sub-MIC tested for each bacterium $(\mathrm{mg} / \mathrm{mL})$ and its inhibitory effect upon biofilm formation (tube test). 0 - no biofilm formation; + - weak biofilm formation; ++ - moderate biofilm formation; +++ - strong biofilm formation; $\mathrm{C}^{+}$- positive control.

\begin{tabular}{|c|c|c|c|c|c|}
\hline & \multirow[b]{2}{*}{$\mathrm{C}^{+}$} & \multicolumn{2}{|c|}{ HMW } & \multicolumn{2}{|c|}{ LMW } \\
\hline & & $1 / 2$ & $1 / 4$ & $1 / 2$ & $1 / 4$ \\
\hline P. gingivalis & +++ & 0 & 0 & 0 & 0 \\
\hline T. forsythensis & +++ & ++ & ++ & 0 & ++ \\
\hline Pr. Buccae & +++ & 0 & + & 0 & ++ \\
\hline A. actinomycetemcomitans & +++ & 0 & 0 & ++ & ++ \\
\hline Pr. intermedia & +++ & ++ & ++ & ++ & ++ \\
\hline
\end{tabular}

defined objective: the batch assay allowed the assessment of the capability of chitosan to inhibit/impede initial adherence of bacteria, whereas the fed-batch assay allowed the study of the capability of chitosan to inhibit biofilm formation under optimum conditions for biofilm development and, as can be seen from Figure 1, chitosan was extremely efficient.

Analysis of the results show that for P. gingivalis (Figure 1(a)) there were no differences between MW and concentrations in the $48 \mathrm{~h}$ assay (batch assay), with all concentrations tested presenting inhibition percentages between 65 and $70 \%$. In the fed-batch assays (96 and 168h) there were clear differences between MW and concentrations with clear differences between concentrations of the same MW being found at 96h. More particularly, the higher concentrations of each MW presented higher inhibition percentages. At $96 \mathrm{~h}$, of all tested conditions, only LMW chitosan, at $0.5 \mathrm{mg} / \mathrm{mL}$, presented inhibition percentages superior to $75 \%$. The remaining conditions presented inhibition values varying between 65 and $77 \%$. When considering the results obtained after $168 \mathrm{~h}$, it is possible to see that both the MW and the concentration of chitosan influenced the results obtained. Of both MW tested, HMW chitosan presented the highest inhibition percentage (88\%) at the highest concentration used, $0.5 \mathrm{mg} / \mathrm{mL}$. On the other hand, for LMW chitosan, the opposite behaviour was observed with the lowest concentration tested, $0.25 \mathrm{mg} / \mathrm{mL}$, presenting the highest inhibition value (82\%). On the other hand, P. intermedia (Figure 1(b)) only presented inhibition percentages above $75 \%$ after $168 \mathrm{~h}$ and only for HMW chitosan. With the exception of the batch assay (48h) there are clear differences between MW in all assays with HMW chitosan presenting higher inhibition percentages overall and with LMW inhibition values reaching as low as $37 \%$ (96h; $0.5 \mathrm{mg} / \mathrm{mL})$.

Prevotellabuccae (Figure 1(c)) presented no differences between MW exhibiting percentages above $75 \%$ in all assays with the only exception being the $96 \mathrm{~h}$ fed-batch assay, which presented a significant drop in inhibition percentages for 0.75 $\mathrm{mg} / \mathrm{mL}$ and $0.25 \mathrm{mg} / \mathrm{mL}$ of HMW and LMW chitosan respectively. Tannerelaforsythensis (Figure 1(d)) showed a similar behaviour to $P$. buccae, with all assays presenting inhibition percentages above $75 \%$ with the exception being $0.25 \mathrm{mg} / \mathrm{mL}$ of HMW which presented inhibition percentages under $20 \%$. For the remaining concentrations there were no significant differences in all tested assays. Aggregatibacter actinomycetemcomitans (Figure 1(e)) presented clear differences in behaviour between concentrations of the same MW, with higher concentrations presenting higher inhibition percentages in all assays. The results obtained after $48 \mathrm{~h}$ showed that $2.5 \mathrm{mg} / \mathrm{mL} \mathrm{HMW}$ and $1.5 \mathrm{mg} / \mathrm{mL} \mathrm{LMW}$ presented, statistically significant, higher $(\mathrm{p}<0.05)$ inhibition percentages than the remaining conditions tested, with biofilm formation inhibition percentages superior to $75 \%$. On the other hand, for the $96 \mathrm{~h}$ and $168 \mathrm{~h}$ assay all the tested conditions presented inhibition values of aprox. $70 \%$. The only exceptions were observed for $0.75 \mathrm{mg} / \mathrm{mL}$ of LMW chitosan which, at $96 \mathrm{~h}$, presented a significantly lower $(\mathrm{p}<0.05)$ inhibition value and for $1.25 \mathrm{mg} / \mathrm{mL}$ of HMW chitosan which, at $168 \mathrm{~h}$, presented a significantly higher $(\mathrm{p}<0.05)$ inhibition value. 

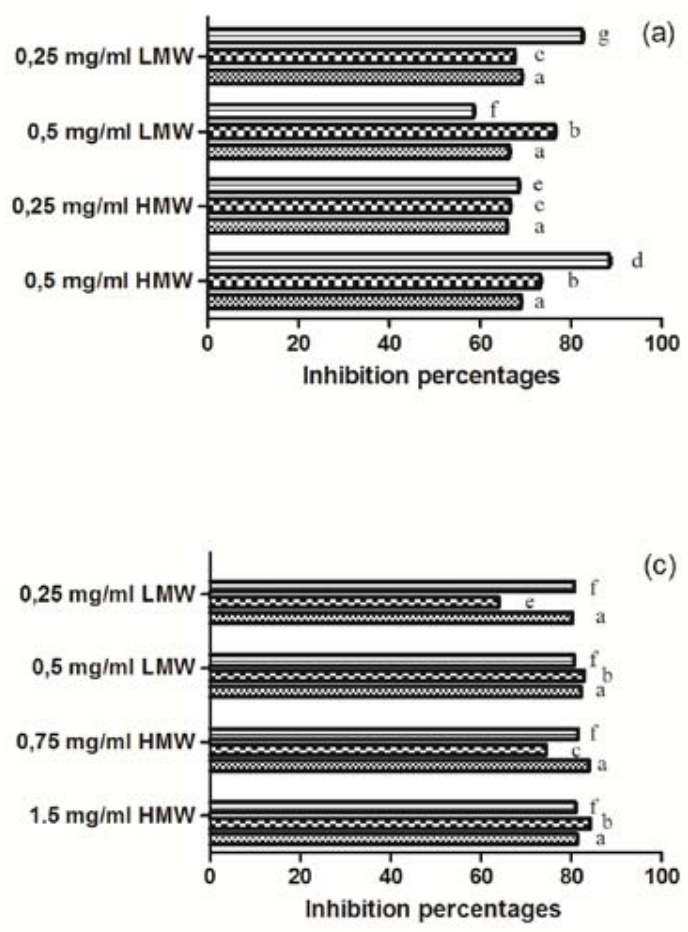

(c)

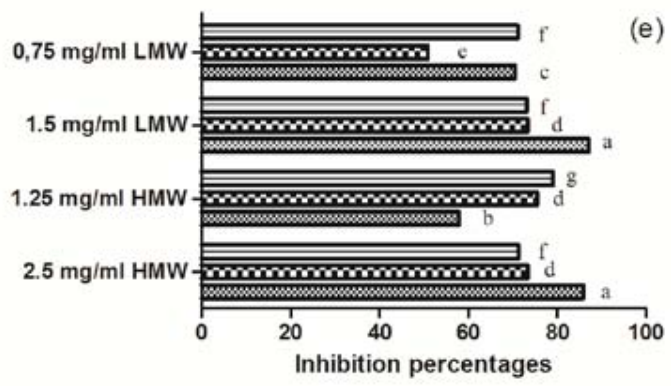

)
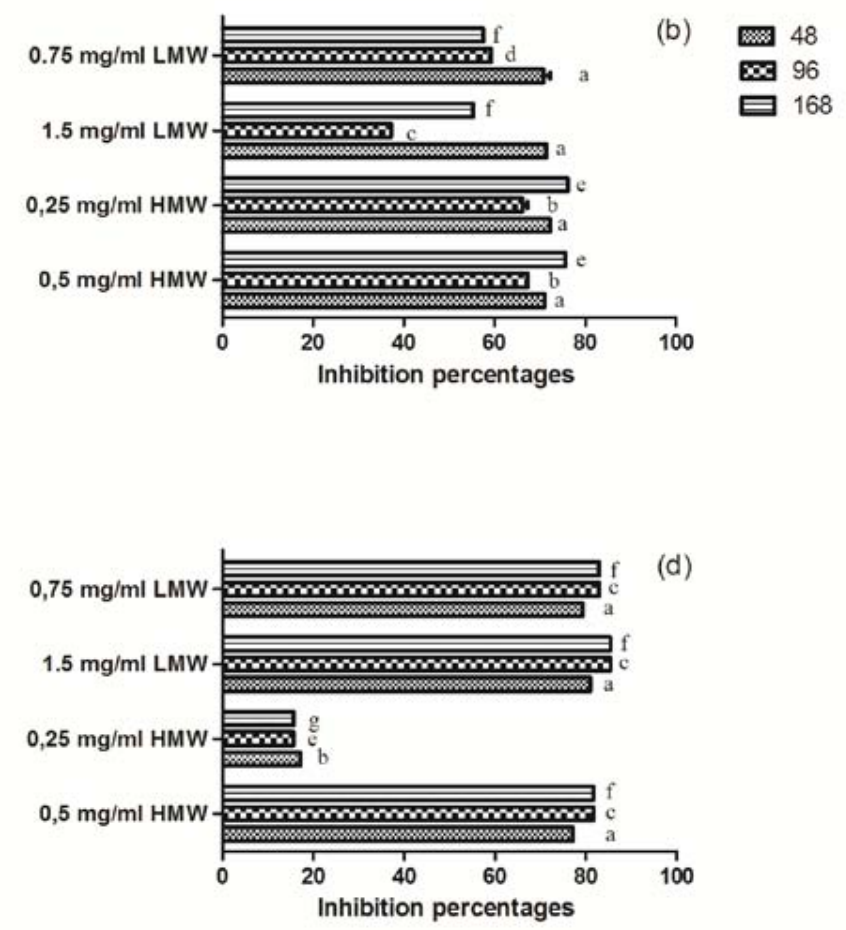

(d)

Figure 1: Inhibitory effect of chitosan on biofilm formation at $48 \mathrm{~h}$ (batch assay), 96 and $168 \mathrm{~h}$ (fed-batch assays) in the microtiter-plate assay. a) $P$. gingivalis; b) Pr. intermedia; c) Pr. buccae; d) T. forsythensis; e) A. actinomycetemcomitans; All assays were done in triplicate.

Previously, Carlson, et al. [21] reported that chitosan was capable of inhibiting up to $99 \%$ of bacterial adhesion to chitosan coated surfaces, thus supporting our results in terms of chitosan's capability of inhibiting adhesion and biofilm formation of oral pathogenic bacteria.

\section{Dual species biofilms}

As bacterial co-aggregation is a key step in biofilm formation an in vitro model using $S$. mutans, a microorganism known to be fundamental in the adhesion process of secondary colonizers $[22,23]$,was used to better ascertain the effect of chitosan in the interaction of $P$. intermedia and $P$. gingivalis with this microorganism. As can be seen in Figure 2 there are clear differences in behaviour between both MWs depending on the co-aggregation pair being tested. While the interaction between
P. intermedia and S. mutans with HMW chitosan presented the highest inhibition percentages for both sub-MIC concentrations tested, for the P. gingivalis/S. mutans pairing no clear differences between MW were found. On a closer look it is possible to see that for the first pair statistically significant $(p<0.05)$ differences were present between the MWs (with HMW chitosan presenting inhibition values $30 \%$ higher than those of LMW chitosan) and the higher the concentration of chitosan the highest the inhibition of biofilm formation. The HMW chitosan inhibition values were arounded $70-80 \%$ in both tested concentrations, while for LMW chitosan the obtained values were around $30-45 \%$. On the other hand for the $P$. gingivalis/S. mutans interaction, despite the absence of statistically significant ( $p>0.05$ ) differences in activity between chitosan MWs, there was a statistically significant difference $(\mathrm{p}<0.05)$ between HMW chitosan concentrations with 
$0.25 \mathrm{mg} / \mathrm{mL}$ of HMW chitosan showing inhibition percentages inferior to those of the remaining concentrations. In this assay, all inhibition values were above $50 \%$ for all chitosan concentrations with $55 \%$ being the lowest inhibition value found $(0.25 \mathrm{mg} / \mathrm{mL}$ HMW) and $69.6 \%$ being the highest $(0.5 \mathrm{mg} / \mathrm{mL} \mathrm{HMW})$.

It is interesting to note that, despite expecting LMW chitosan to present higher activity against both co-aggregation processes (LMW chitosan is described as acting better upon Gram negative bacteria) [11], we found a mixed behaviour, with HMW chitosan being more effective when P. intermedia was present and with no differences when $P$. gingivalis was tested. These results come in line with those of previous studies [10] which showed that, for HMW chitosan, concentration would be a key factor in its activity in polymicrobial biofilm formation and that HMW chitosan would be a better alternative against co-aggregation as it is equally active against biofilms formed only by Gram positive and Gram negative mixed biofilms.

Despite the lack of studies regarding the effect of chitosan upon co-aggregation our results show that chitosan is active upon co-aggregation partners preventing the formation of a polymicrobial biofilm.

\section{Quorum sensing inhibition}

The capacity of chitosan to inhibit QS, in this particular case through the inhibition of $\mathrm{N}$-acyl-homoserine lactones, the most common QS autoinducer for Gram negative bacteria, was evaluated using the biosensor strain $C$. violaceum. Compared to the control, the tested chitosan MWs significantly ( $\mathrm{p}<0.005$ ) reduced the production of violacein by $C$. violaceum at both subMIC concentrations (MIC assay data not shown) assayed (Figure 3). The capacity of chitosan to inhibit QS seems to be concentration dependent, with the lowest concentrations of both MWs presenting statistically significantly $(\mathrm{p}<0.05)$ higher inhibitions percentages, and MW dependent, with HMW chitosan presenting

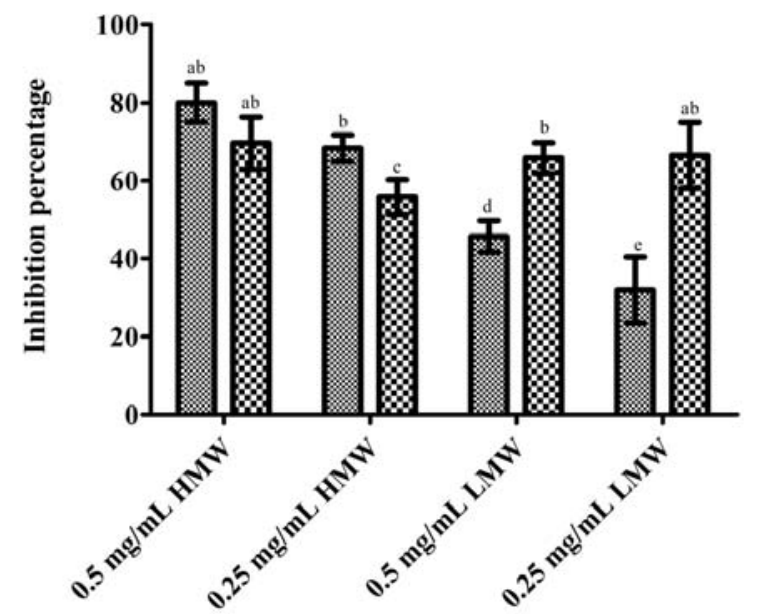

Figure 2: Effect of sub-MIC concentrations of chitosan upon dual-species biofilm formation. - S. mutans and P. intermediabiofilm formation;

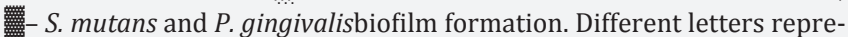
sent the statistical differences found.

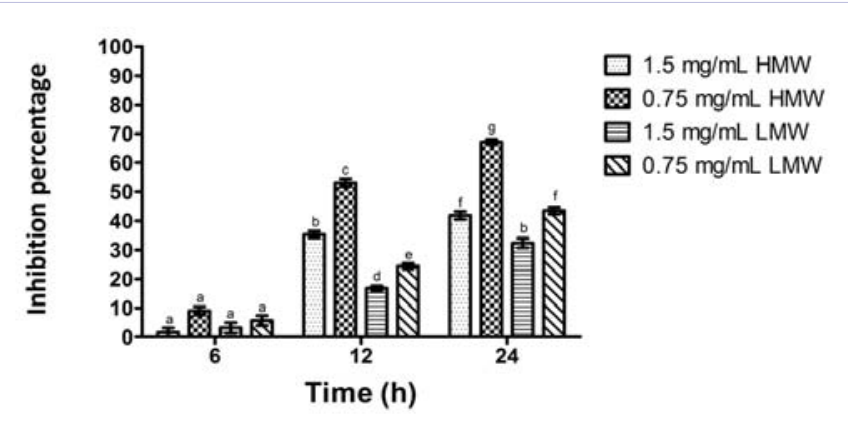

Figure 3: Effect of sub-MIC concentrations of chitosan upon C. violaceumviolacein production. Different letters represent the statistical differences found.

significantly higher inhibition percentages. It is important to note that chitosan's activity increased with the course of the assay with QS inhibition percentages reaching 67\% for HMW and 43\% for LMW after $24 \mathrm{~h}$ exposure to chitosan. Considering the known properties of chitosan there are a few possible explanations for the results obtained. As several authors have reported [9,12,24], HMW chitosan activity is focused upon the bacterial membrane and as such it is possible that this disruption may interfere with C. violaceumviolacein production metabolism. When looking into LMW chitosan the same authors described that it was capable of entering the bacterial cell where it interfered with cellular machinery, as such it is possible that LMW chitosan is interfering in the violacein metabolic synthesis, possibly through interaction with violacein metabolic precursor prodeoxyviolacein, which synthesis involves a four-electron oxidative step [25].

\section{Conclusions}

Chitosan showed a strong effect against periodontal pathogens throught the inhibition of biofilm formation, with activity being registered even after $168 \mathrm{~h}$, and against dual species biofilms, thus indicating that chitosan may interfere with bacterial coaggregation. Furthermore, chitosan was capable of inhibiting $C$. violaceum violacein production, a known QS reporter system, therefore showing a potential to disturb biofilm formation by QS inhibition.

Despite promising these results still require a further studies in order to better understand chitosan's activity upon oral pathogens biofilm formation. The influence of conditions like salivary flow and biotic and abiotic factors presence over chitosan activity still have to be assessed as they may hamper chitosan's effect upon biofilms. Nonetheless the results here obtained reinforce the potential of chitosan as a natural alternative for dental biofilm control and oral disease treatment with potential to be active component in future oral health formulations.

\section{Acknowledgements}

The author hereby gratefully acknowledges the Agency of Innovation (Agencia de Inovacao, ADI, Portugal) and Quadro de Referencia Estrategico Nacional (QREN, Portugal) which through the project "QUITORAL - Desenvolvimento de novasformulacoes de quitosanos com aplicacaoemmedicina oral” (QREN-ADI 3474) 
and the National Funds from FCT - Fundacao para a Ciencia e a Tecnologia through project PEst-OE/EQB/LA0016/2011 provided funding for the realization of this work.

\section{References}

1. An YH, Friedman RJ (2010) Handbook of bacterial adhesion: principles, methods and applications. Humana Press, Totowa, United States.

2. Shams TK, Maqusood A, Abdulaziz AK, Javed M (2013) Biocidal effect of copper and zinc oxide nanoparticles on human oral microbiome and biofilm formation. Materials Letters 97: 67-70.

3. Rupf S, Balkenhol M, Sahrhage TO, Baum A, Chromik JN, et al. (2012) Biofilm inhibition by an experimental dental resin composite containing octenidine dihydrochloride. Dent Mater 28(9): 974-984.

4. Kolenbrander PE, Palmer RJ, Rickard AH, Jakubovics NS, Chalmers $\mathrm{NI}$, et al. (2006) Bacterial interactions and successions during plaque development. Periodontol 2000 42: 47-79.

5. Willey JM, Sherwood L, Woolverton CJ (2008) Prescott, Harley, and Klein's microbiology. McGraw-Hill Higher Education, United Kingdom.

6. Schwach AK, Vivien CN, Gurny R (2000) Local delivery of antimicrobial agents for the treatment of periodontal diseases. Eur J Pharm Biopharm 50(1): 83-99.

7. Mims CA (2004) Medical microbiology. ( $3^{\text {rd }}$ edn), Mosby, United States.

8. Busscher HJ, Engels E, Dijkstra RJ, van der Mei HC (2008) Influence of a chitosan on oral bacterial adhesion and growth in vitro. Eur J Oral Sci 116(5): 493-495.

9. Costa EM, Silva S, Pina C, Tavaria FK, Pintado MM (2012) Evaluation and insights into chitosan antimicrobial activity against anaerobic oral pathogens. Anaerobe 18(3): 305-309.

10. Costa EM, Silva S, Tavaria FK, Pintado MM (2013) Study of the effects of chitosan upon Streptococcus mutans adherence and biofilm formation. Anaerobe 20: 27-31.

11. Fernandes JC, Eaton P, Gomes AM, Pintado ME, Xavier Malcata F (2009) Study of the antibacterial effects of chitosans on Bacillus cereus (and its spores) by atomic force microscopy imaging and nanoindentation. Ultramicroscopy 109(8): 854-860.

12. Raafat D, HG Sahl (2009) Chitosan and its antimicrobial potential--a critical literature survey. Microb Biotechnol 2(2): 186-201.

13. Kockisch S, Rees GD, Tsibouklis J, Smart JD (2005) Mucoadhesive, triclosan-loaded polymer microspheres for application to the oral cavity: preparation and controlled release characteristics. Eur J Pharm Biopharm 59(1): 207-216.

14. Choi BK, Kim KY, Yoo YJ, Oh SJ, Choi JH, et al. (2001) In vitro antimicrobial activity of a chitooligosaccharide mixture against Actinobacillus actinomycetemcomitans and Streptococcus mutans. Int J Antimicrob Agents 18(6): 553-557.

15. Bae K, Jun EJ, Lee SM, Paik DI, Kim JB (2006) Effect of water-soluble reduced chitosan on Streptococcus mutans, plaque regrowth and biofilm vitality. Clin Oral Investig 10(2): 102-107.

16. Hayashi Y, Ohara N, Ganno T, Ishizaki H, Yanagiguchi K (2007) Chitosan-containing gum chewing accelerates antibacterial effect with an increase in salivary secretion. J Dent 35(11): 871-874.

17. Christensen GD, Simpson WA, Bisno AL, Beachey EH (1982) Adherence of Slime-Producing Strains of Staphylococcus epidermidis to Smooth Surfaces. Infect Immun 37(1): 318-326.

18. Stepanovic S, Vukovic D, Dakic I, Savic B, Svabic VM (2000) A modified microtiter-plate test for quantification of staphylococcal biofilm formation. J Microbiol Methods 40(2): 175-179.

19. Pitlovanciv AK, Caris ME, Porto LM, Pedrosa RC, Antonio RV (2006) Condicoes de cultivo e producao de pigmentos por Chromobacterium violaceum. Biotemas 19(1): 13-18.

20. Cerca N, Pier GB, Vilanova M, Oliveira R, Azeredo J (2004) Influence of batch or fed-batch growth on Staphylococcus epidermidis biofilm formation. Lett Appl Microbiol 39(5): 420-424.

21. Carlson RP, Taffs R, Davison WM, Stewart PS (2008) Anti-biofilm properties of chitosan-coated surfaces. J Biomater Sci Polym Ed 19(8): 1035-1046.

22. Deng DM, Hoogenkamp MA, Exterkate RA, Jiang LM, van der Sluis LW, et al. (2009) Influence of Streptococcus mutans on Enterococcus faecalis Biofilm Formation. J Endod 35(9): 1249-1252.

23. Jiang LM, Hoogenkamp MA, van der Sluis LW, Wesselink PR, Crielaard W, et al. (2011) Resazurin metabolism assay for root canal disinfectant evaluation on dual-species biofilms. J Endod 37(1): 31-35.

24. Fernandes JC, Tavaria FK, Soares JC, Ramos OS, Joao MM, et al. (2008) Antimicrobial effects of chitosans and chitooligosaccharides, upon Staphylococcus aureus and Escherichia coli, in food model systems. Food Microbiol 25(7): 922-928.

25. Balibar CJ, Walsh CT (2006) In vitro biosynthesis of violacein from L-tryptophan by the enzymes VioA-E from Chromobacterium violaceum. Biochemistry 45(51): 15444-15457. 